\title{
COMPARATIVE NUMERICAL ANALYSIS OF HIGH LIFT AIRFOILS AND EFFECT OF MACH NUMBERS USING CFD
}

\author{
Aravind Satheesh Kumar ${ }^{1}$, Tarun Yadav $^{2}$, Bharat Singh Mandloi ${ }^{3}$, RP Khapli ${ }^{4}$ \\ ${ }^{I}$ Graduate Student, Department of Aerospace Engineering, SRM University, Kanttankulathur, Tamil Nadu, India \\ ${ }^{2}$ Senior Manager, AURDC, Hindustan Aeronautics Limited, Nasik, India \\ ${ }^{3}$ Scientist-F, Regional Center For Military Airworthiness, Nasik, India \\ ${ }^{4}$ Addl. General Manager, AURDC, Hindustan Aeronautics Limited, Nasik, India
}

\begin{abstract}
This paper focuses on the comparative numerical analysis of two high lift airfoil's geometries using Computational Fluid Dynamics. Two airfoil's MDA3OP30N and S1223RTL were chosen for the analysis at various angle of attack. Three Mach Numbers mainly $0.2 \mathrm{M}, 0.6 \mathrm{M}$ and $0.8 \mathrm{M}$ were considered for the analysis. The simulations were carried out at atmospheric conditions similar to an altitude of 40,000ft, which is the altitude used commonly by aviation airplanes for cruising. The flow features like pressure variation, velocity distribution, turbulent viscosity variation, streamline distribution and eddy loop formations along with aerodynamic coefficients like Coefficients of Lift and Drag were studied and analyzed. The CFD results of MDA30P30N was validated with the experimental results. It is concluded that multi element airfoil MDA30P30N gives better aerodynamic performance than single element airfoil S1223RTL. Hence, it is prudent to use multi-element airfoils than single element high lift generating airfoils in general aviation aircraft.
\end{abstract}

Keywords: Aerodynamics, Computational Fluid Dynamics (CFD), Drag coefficient, Mach number, Multi-element, High-lift devices, Airfoil, Lift coefficient, Unmanned Aerial Vehicle(UAV).

\section{NOMENCLATURE}

$u=$ Velocity

$\alpha=$ Angle of attack

$\rho=$ Density

$p=$ Pressure

$\sigma=$ Shear stress

$\mu=$ Dynamic viscosity

$f=$ Force

$M=$ Mach number

$R e=$ Reynolds number

$C_{L}=$ Coefficient of lift

$C_{D}=$ Coefficient of drag

$C p=$ Coefficient of pressure

$x, y, z=$ Cartesian co-ordinates

Sub-scripts

$i, j, z=$ Directions in $x, y, z$ respectively

$L=$ Lift

$D=$ Drag

\section{INTRODUCTION}

An airplane's lift generating capacity majorly lies on its wings, which affects its overall performance. An airfoil is a core from which a design of a wing is made. Hence, the airfoil is the first step towards the making of a wing which fulfills the characteristics of lift generation and stability required by the airplane. When high lift generation is the priority, there are ways in which it is achieved, use of multi element as a wing geometry and usage of High-lift generating airfoils on making the wings are two such ways, of which first is majorly used by the commercial industry for its many other advantages.

In usage of High-lift devices, the airfoil consists of multiple elements. These multiple elements play an important role in the generation and increment of the lift generated by the main airfoil. The High-Lift generation capability of an aircraft is also responsible for its take-off performance, landing performance and low-speed maneuverability, therefore it is an integral part in the design of military and commercial aircraft. Improved performance in high-lift can lead to increased range and payload as well as decreased landing speed and field length requirements[1]. General high-lift system for an aircraft often consists of a basic wing with a leading-edge slat and trailing-edge flap elements, but as the number of elements increases so does its complexity as compared to the single element high-lift generating airfoil.

Therefore, this paper aims to bring out an analytical comparison between a multi-element airfoil and a single element airfoil in order to contribute data on the selection of best airfoil geometry while designing of the wing for an airplane. In this paper, the comparative analysis has been done on McDonnell Douglas MDA30P30N(Figure 1), multi-element airfoil and S1223RTL(Figure 2), a modification of the S1223 airfoil by Richard T. LaSalle[4] which is a single element high-lift generating airfoil on varying Mach numbers and Angles of attack at the altitude of 40,000ft. 


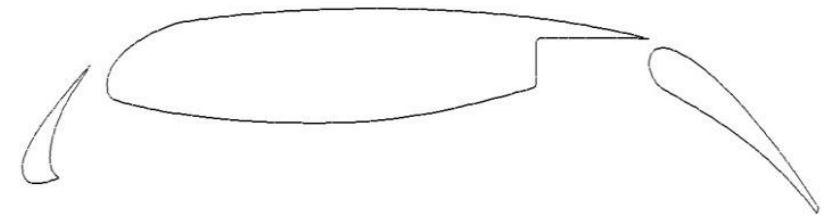

Fig 1: MDA30P30N multi-element airfoil

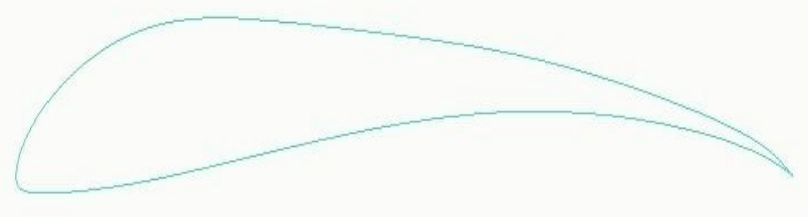

Fig 2: S1223RTL single element airfoil

In a comparative analysis, it is important to understand thoroughly the behaviour of fluid flow, defined by means of various characteristics like pressure and viscous forces, drag coefficient, eddy loops around the body as this assists in basic design. The CFD tools was used for carrying out the numerical analysis as it is the strongest tool in current scenario to solve Euler equations precisely, Many studies in the past have shown, results produced in the CFD software are similar to the wind tunnel experiments done on the same specimen. Also, retrieving data from the software is much convenient saving time and energy. Thus, a comparative analysis was achieved by the use of CFD for accurate numerical predictions of the flow over different airfoils.

\section{LITERATURE SURVEY}

Zhenhui Zhang et al[1], performed a numerical investigation of flow over multi-element airfoils with lift enhancing tabs. In the study, they investigated multi-element airfoils with flat-plate lift-enhancing tabs placed near the trailing edge of the main element or/and flap for different flap riggings. The effects of local grid near the lift-enhancing tabs on computational results and also various tabs were studied for McDonnell Douglas Aerospace three-element airfoils consisting of a slat and single-slotted flap. In their results they found, cove tabs reduced the sensitivity of the lift of the multi-element airfoil to the size of the flap gap and may help to reoptimize an airfoil with the flap in non-optimum position. The flap tabs increased the lift and pitching moment coefficients with little drag penalty due to the increased aft camber of the flap. Adding a cove tab and a flap tab simultaneously to the baseline configuration appeared to produce a linear combination of the changes caused by the individual tabs.

In the recent study done by Udaya Kumar D et al[2], the flow over multi-element airfoils was numerically investigated and was compared to the aerodynamic parameters of the standard NACA airfoils 4412 and 0012. The analysis was conducted by keeping the flow inlet velocity at $10 \mathrm{~m} / \mathrm{s}$ over different angles of attack $\left(0^{\circ}, 2^{\circ}, 4^{\circ}\right.$, $6^{\circ}, 8^{\circ}, 10^{\circ}, 12^{\circ}$ and $14^{\circ}$ ), flow properties and aerodynamic forces. Numerical results of which showed that the aerodynamic parameters of multi element airfoils with tail effect were much more optimum than the standard NACA airfoils.

Christopher L. Rumsey et al[3], did an experiment on threedimensional effects on multi-element high lift computations. it was an effort to discover the causes for disagreement between 2-D computations and nominally 2-D experiment for flow over the 3-element McDonnell Douglas 30P-30N airfoil configuration at high lift. The experiment explored several different side-wall boundary layer control venting patterns, documented venting mass flow rates, and looked at corner surface flow patterns. Unstructured-grid computations demonstrated that mounting brackets lower the lift levels near maximum lift conditions.

Sumeet Sharma [4], did a comparative analysis of airfoils of low-speed aircraft. It included CFD analysis of S1223, S819, S8037 and S1223RTL. Spalart-Allmaras (1 equation) flow equation was chosen for the analysis of flowing fluid. The flowing fluid was considered as Air- Ideal gas and the flow of the flowing fluid was steady. For the analysis of airfoils, the Mach Numbers $\mathrm{M}=0.10,0.15,0.20,0.25$ and 0.30 were applied on each of the airfoils for their comparative analysis. It was concluded that the S1223RTL airfoil had the most suitable design for the specified boundary conditions and the Mach numbers from 0.10 to 0.30 .

W. Kyle Anderson et al[5], did an experiment on a twodimensional unstructured Navier-Stokes code utilized for computing the flow around multi-element airfoil configurations. In the experiment, comparisons were shown for a landing configuration with an advanced-technology flap. Grid convergence studies are conducted to assess inaccuracies caused by inadequate grid resolution. For the advanced flap configuration, comparisons of pressure distributions and lift were made with experimental data. There, two flap riggings and two Reynolds numbers were considered. In general, the trends caused by variations in the quantities were well predicted by the computations, although the angle of attack for the maximum lift was over predicted.

Prashant $\mathrm{J}$ Ambhore et al[6], in their experiment, made an effort to address the issue of space junk, by making use of the UAVs that can fly in high altitude and low Reynolds' number. Their aim was to suggest the use multi element airfoil in the wings of a UAV over the single airfoil of the wing to increase its efficiency in the work environment of the stratosphere. After addressing the problem on computational tools, it was found that multi element airfoils significantly increased the maximum lift coefficient. 


\section{GOVERNING EQUATIONS}

Continuity equation:

$$
\frac{\partial \rho}{\partial t}+\frac{\partial}{\partial x} \rho u_{x}+\frac{\partial}{\partial y} \rho u_{y}+\frac{\partial}{\partial z} \rho u_{z}=0
$$

Equation of motion:

Where $\rho$ and $\mu$ are constants,

$\rho\left(\frac{\partial u_{x}}{\partial t}+u_{x} \frac{\partial u_{x}}{\partial x}+u_{y} \frac{\partial u_{x}}{\partial y}+u_{z} \frac{\partial u_{x}}{\partial z}\right)=-\frac{\partial p}{\partial x}+\mu\left[\frac{\partial^{2} u_{x}}{\partial x^{2}}+\frac{\partial^{2} u_{x}}{\partial y^{2}}+\frac{\partial^{2} u_{x}}{\partial z^{2}}\right]+\rho g_{x}$

$\rho\left(\frac{\partial u_{y}}{\partial t}+u_{x} \frac{\partial u_{y}}{\partial x}+u_{y} \frac{\partial u_{y}}{\partial y}+u_{z} \frac{\partial u_{y}}{\partial z}\right)=-\frac{\partial p}{\partial y}+\mu\left[\frac{\partial^{2} u_{y}}{\partial x^{2}}+\frac{\partial^{2} u_{y}}{\partial y^{2}}+\frac{\partial^{2} u_{y}}{\partial z^{2}}\right]+\rho g_{y}$

$\rho\left(\frac{\partial u_{z}}{\partial t}+u_{x} \frac{\partial u_{z}}{\partial x}+u_{y} \frac{\partial u_{z}}{\partial y}+u_{z} \frac{\partial u_{z}}{\partial z}\right)=-\frac{\partial p}{\partial z}+\mu\left[\frac{\partial^{2} u_{z}}{\partial x^{2}}+\frac{\partial^{2} u_{z}}{\partial y^{2}}+\frac{\partial^{2} u_{z}}{\partial z^{2}}\right]+\rho g_{z}$

The core basic equations used for fluid simulation by CFD are Navier-Stokes equations which are given by,

$$
\rho\left[\frac{d u}{d t}+u \nabla u\right]=\nabla \sigma+f
$$

$\rho$ is equivalent to mass, $\left[\frac{d \boldsymbol{k}}{d t}+\boldsymbol{k} \nabla \boldsymbol{u}\right]$ is the acceleration,

$\nabla \sigma+f$ represents the total force, in which the $\mathrm{f}$ being all other forces acting on the body.

Another form of Navier-Stokes equation is given by,

$$
\rho \frac{d u}{d t}=-\nabla p+\mu \nabla^{2} u+f
$$

Here $\nabla^{2}$ is the Laplacian operator

These equations are a set of nonlinear partial differential equations (PDEs) with assigned boundary conditions. The continuity equation and the general form of the NavierStokes equations, in tensor notation are,

$$
\frac{\partial p}{\partial t}+\frac{\partial\left(p \boldsymbol{k}_{i}\right)}{\partial \boldsymbol{x}_{i}}=\mathbf{O}
$$

$$
\frac{\partial\left(\rho u_{i}\right)}{\partial t}+\frac{\partial\left(\rho u_{i} u_{j}\right)}{\partial x_{i}}=-\frac{\partial \rho}{\partial x_{i}}+\frac{\partial}{\partial x_{i}}\left[\mu\left(\frac{\partial u_{i}}{\partial x_{j}}+\frac{\partial u_{j}}{\partial x_{i}}\right)\right]+F
$$

The eq. 3.7 and eq. 3.8 is the instantaneous acceleration term and the convection term respectively. It consists of the pressure gradient term plus the viscous dissipation term. In case of incompressible flows $\rho$ constant.

\section{NUMERICAL DESIGN AND MODELLING}

The comparative analysis of both the airfoil section was mainly associated with the principle feature i.e. the geometry. Therefore, at first 2D design of both the airfoils were created, their coordinates were imported into ANSYS ICEM CFD 15.0 for further processing. The coordinates [10],[11] were joined to obtain the curvature of the airfoil. Each part was named separately, in the case of MDA30P30N (Figure 1) it had 3 parts viz. slats, main body and flaps, and in S1223RTL (Figure 2) it had only one part viz. the main body.

Once the geometry was made including the curves and points. The far field was created for both the geometries. The shape of the far field was chosen to be a combination of a rectangle and a semicircle as can be seen in Figure 3. The dimensions were so taken that, the distance from the surface of the airfoil to the edge of the far field would be approximately 8-11 times the chord length of the airfoil geometry under study.

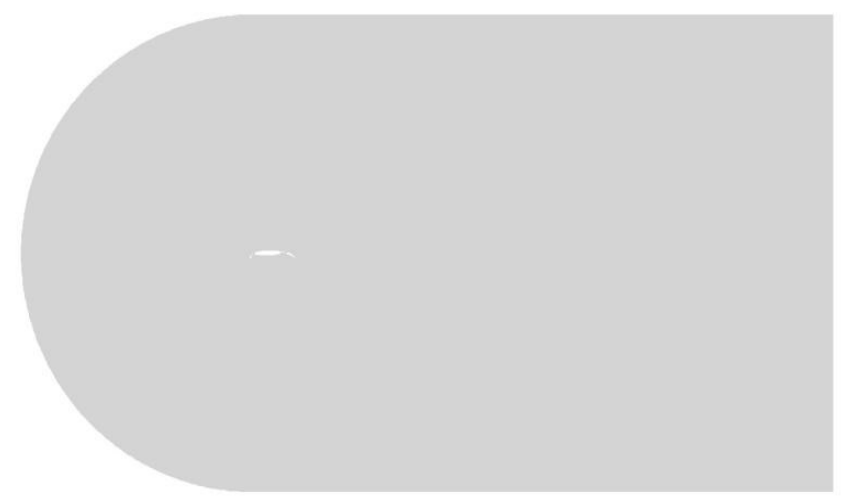

Fig 3: Far-field for the airfoil geometries

\section{ANALYSIS AND SIMULATION}

\subsection{Mesh and Grid Generation}

The meshing for both the airfoil geometries was done by using ICEM CFD software of ANSYS 15.0 package. An unstructured type of mesh was created for both the geometries as can be seen in Figure 4 and 5, using all-tri elements and patch independent mesh method, global element scale factor and global element seed size was kept as 1 and 0.1 respectively. Once, the global mesh was obtained, density boxes were created around the airfoil geometry in each case for the creation of a finer mesh in the immediate surroundings of the airfoils. The dimensions of the density box were 0.5 times the airfoil chord length above 
and below the geometry and 3-4 times the chord length at the leading and trailing edge of the geometry. Figure 4 and 5 also shows the density boxes around both the airfoil geometries. Size of the elements inside the density box was given to be 0.013 in both the cases.

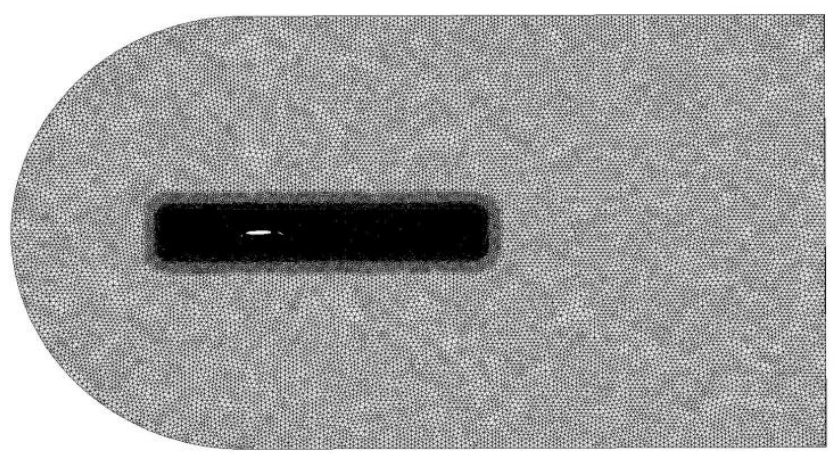

Fig 4: Unstructured mesh over MDA30P30N

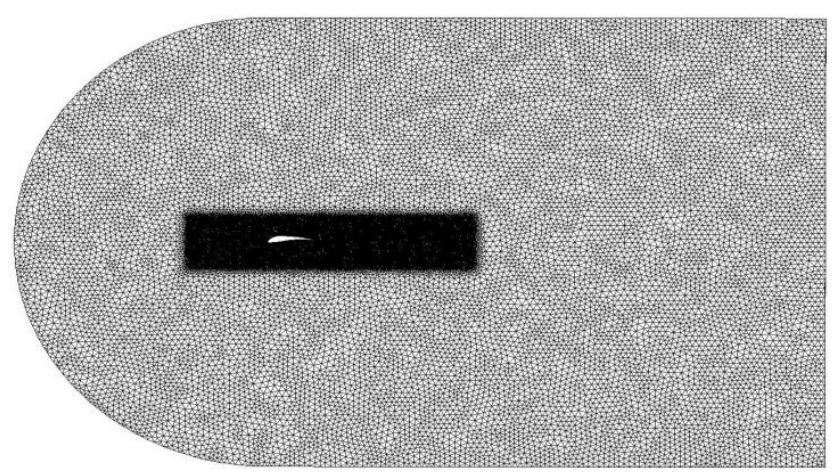

Fig 5: Unstructured mesh over S1223RTL

Capturing of fluid flow around the wall of the geometry is the most important part of the analysis, thus prism layers were created around both the airfoil geometries. The height ratio was kept to be 1.2 and 5 prism layers were generated. Figure 6,7,8 and 9 show the prism layers on both the airfoil geometries. Table 1 shows the number of nodes and a total number of elements in each case. The grids were sufficiently fine near the walls to capture the exact fluid flow physics. After meshing, initialization and boundary conditions were set and CFD simulations in ANSYS Fluent 15.0 were carried out on both grids to analyze the fluid flow behaviour of these airfoil geometries. In Fluent, the dimensional units were set to SI.

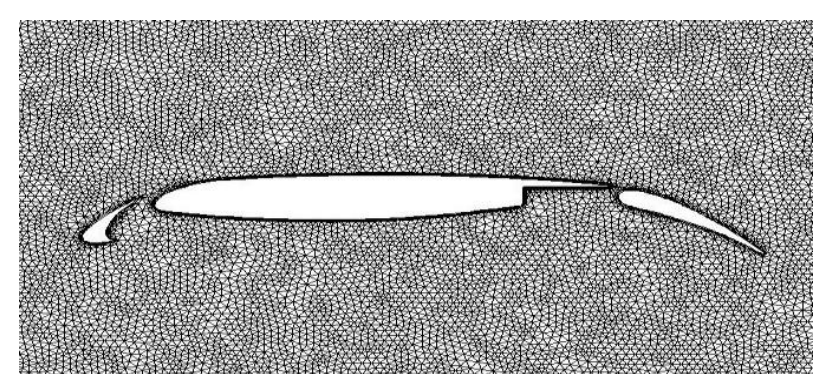

Fig 6: Prism Layers on MDA30P30N

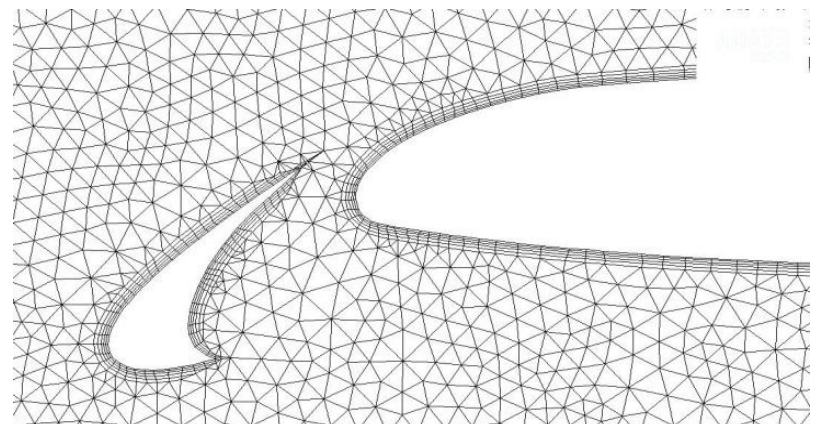

Fig 7: MDA30P30N zoomed in view of the prism layer(Slat $\&$ Main body)

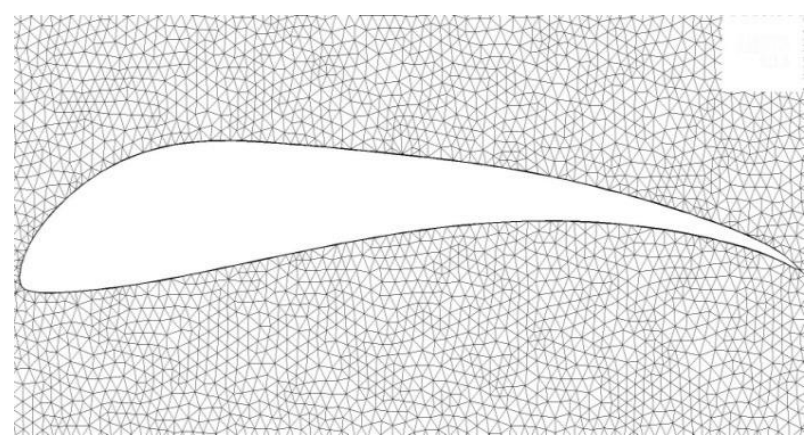

Fig 8: Prism Layers on S1223RTL

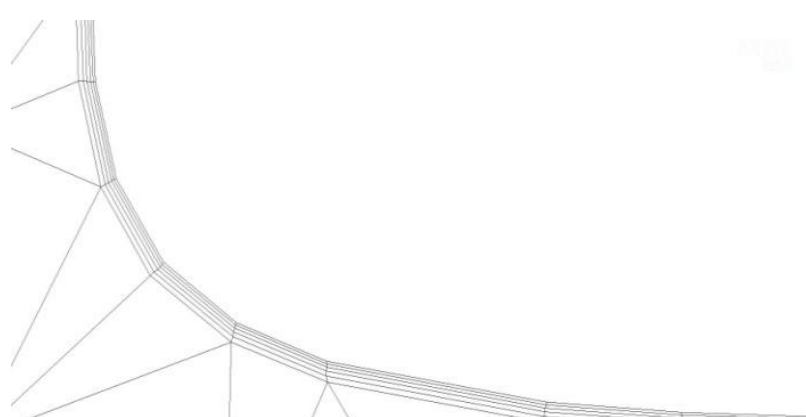

Fig 9: S1223RTL zoomed in view of the prism layer

Table 1: Number of Nodes and Elements

\begin{tabular}{|l|l|l|}
\hline Airfoil & $\begin{array}{l}\text { Total Number of } \\
\text { Nodes }\end{array}$ & $\begin{array}{l}\text { Total Number of } \\
\text { Elements }\end{array}$ \\
\hline MDA30P30N & 89361 & 176642 \\
\hline S1223RTL & 57047 & 112740 \\
\hline
\end{tabular}

\subsection{Discretization and Control Setup}

The density based solver with Spalart-Allmaras equation for the viscous model was considered for simulation. In solution setup, the fluid was set to be air in which density was set to ideal gas configuration and viscosity was set to Sutherland. Generally, commercial aircraft fly at an altitude varying from $30,000 \mathrm{ft}$ to $50,000 \mathrm{ft}$ during their cruise. Therefore, in boundary conditions, the zone type was selected to be Pressure Far-field, under which the Gauge Pressure was set to be $18800 \mathrm{~Pa}$ and Temperature was set to be $216.65 \mathrm{~K}$, for the generation of fluid flow at 40,000ft[12]. The analysis was performed over 3 different Mach numbers viz. $0.2 \mathrm{M}$, $0.6 \mathrm{M}$ and $0.8 \mathrm{M}$ as the general aviation subsonic aircrafts usually take off at around $0.2 \mathrm{M}$ and cruises at $0.6 \mathrm{~m}-0.8 \mathrm{M}$. 
Table 2 shows the different $\mathrm{X}$ and $\mathrm{Y}$ component of flow direction inputs given in each case.

Table 2: Values of Components of Flow

\begin{tabular}{|c|c|c|c|}
\hline Airfoil & $\begin{array}{l}\text { Angle } \\
\text { of } \\
\text { Attack } \\
(\alpha)\end{array}$ & $\begin{array}{l}\text { X } \\
\text { component } \\
\text { of flow } \\
(\operatorname{Sin} \alpha)\end{array}$ & $\begin{array}{l}\text { Y } \\
\text { component } \\
\text { of flow } \\
(\operatorname{Cos} \alpha)\end{array}$ \\
\hline \multirow{7}{*}{ MDA30P30N } & $0^{\circ}$ & 0 & 1 \\
\hline & $4^{\circ}$ & 0.0697 & 0.9976 \\
\hline & $8^{\circ}$ & 0.1392 & 0.9903 \\
\hline & $12^{\circ}$ & 0.2079 & 0.9781 \\
\hline & $16^{\circ}$ & 0.2756 & 0.9613 \\
\hline & $20^{\circ}$ & 0.3420 & 0.9397 \\
\hline & $24^{\circ}$ & 0.4067 & 0.9135 \\
\hline \multirow{5}{*}{ S1223RTL } & $0^{\circ}$ & 0 & 1 \\
\hline & $4^{\circ}$ & 0.0697 & 0.9976 \\
\hline & $8^{\circ}$ & 0.1392 & 0.9903 \\
\hline & $12^{\circ}$ & 0.2079 & 0.9781 \\
\hline & $16^{\circ}$ & 0.2756 & 0.9613 \\
\hline
\end{tabular}

\section{RESULTS AND ANALYSIS}

\subsection{Numerical Validation}

The validation of CFD results was carried by plotting $\mathrm{Cp}$ plot with experimental result. Figure 10 shows the plot of Coefficient of Pressure versus $\mathrm{x} / \mathrm{c}$ at $16^{\circ}$ angle of attack, comparing results of computational and experimental data of the airfoil MDA30P30N[5]. It can be seen that computed pressure distribution result is in good agreement with the experimental measurements.

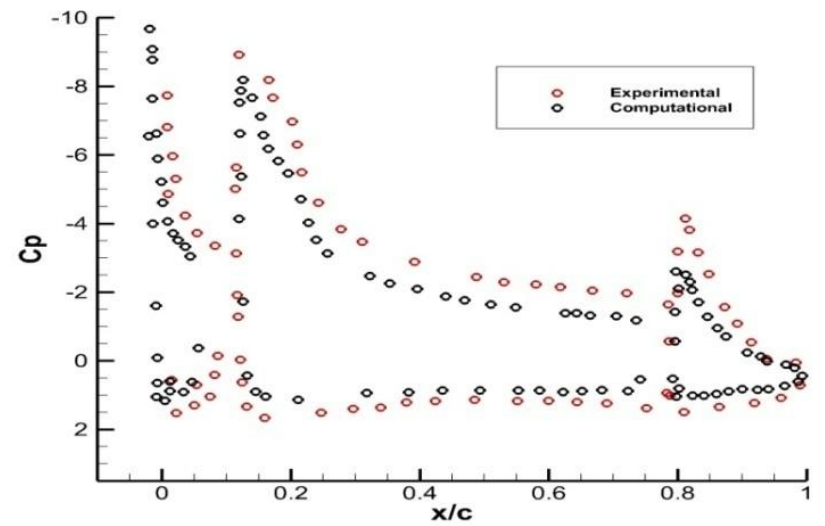

Fig 10: Coefficient of Pressure $(\mathrm{Cp})$ vs. $\mathrm{x} / \mathrm{c}$ plot of MDA30P30N multi element airfoil

\subsection{CFD Results}

The CFD results of the both airfoil geometries were compared analytically. Throughout the simulation, air flow had been kept incompressible and constant. All other parameters such as temperature, density, pressure, and velocity are considered to be independent of time.

Figure 11,12,13 and 14 shows the pressure variation of the airfoil geometries MDA30P30N and S1223RTL at different Mach numbers and Angles of attack. As can be seen, the pressure below the airfoil is far more than the pressure above the wings, which confirm the physics requirement.

Figure 15,16,17 and 18 shows the velocity distribution, the velocity above both the airfoil geometries MDA30P30N and S1223RTL increases as the Angles of Attack and Mach numbers increase. Figure 19 and 20 depict the turbulent viscosity of both airfoil geometries, as can be seen the wake profile of S1223RTL is narrower than the MDA30P30N which results in much less turbulence created by the S1223RTL airfoil geometry.

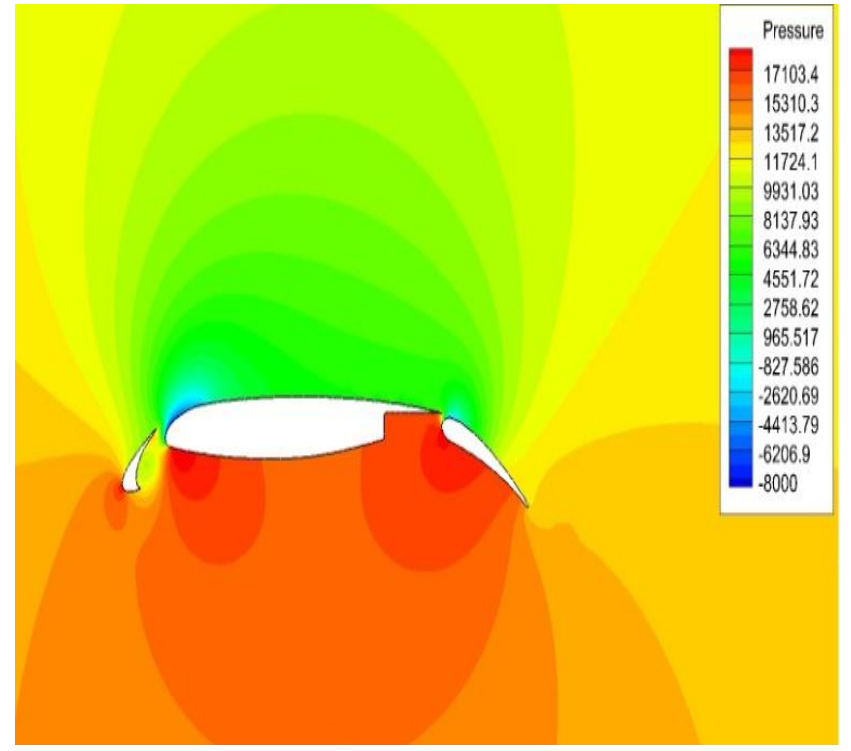

Fig 11: Pressure variation in MDA30P30N airfoil geometry at $\mathrm{M}=0.2$ and $\alpha=4^{\circ}$

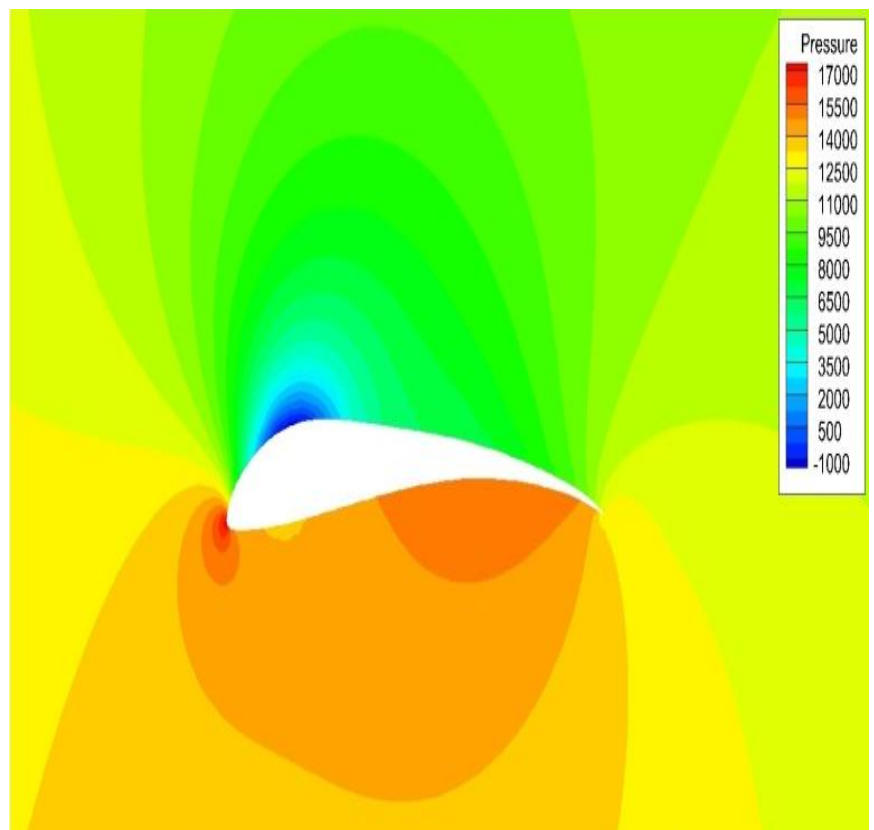

Fig 12: Pressure variation in S1223RTL airfoil geometry at $\mathrm{M}=0.2$ and $\alpha=4^{\circ}$ 


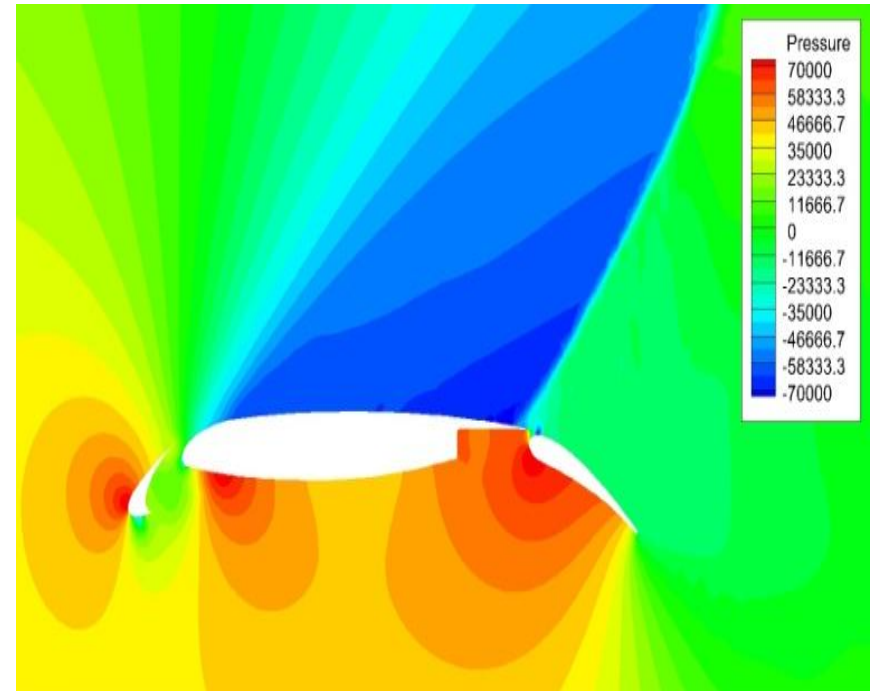

Fig 13: Pressure variation in MDA30P30N airfoil geometry at $\mathrm{M}=0.8$ and $\alpha=8^{\circ}$

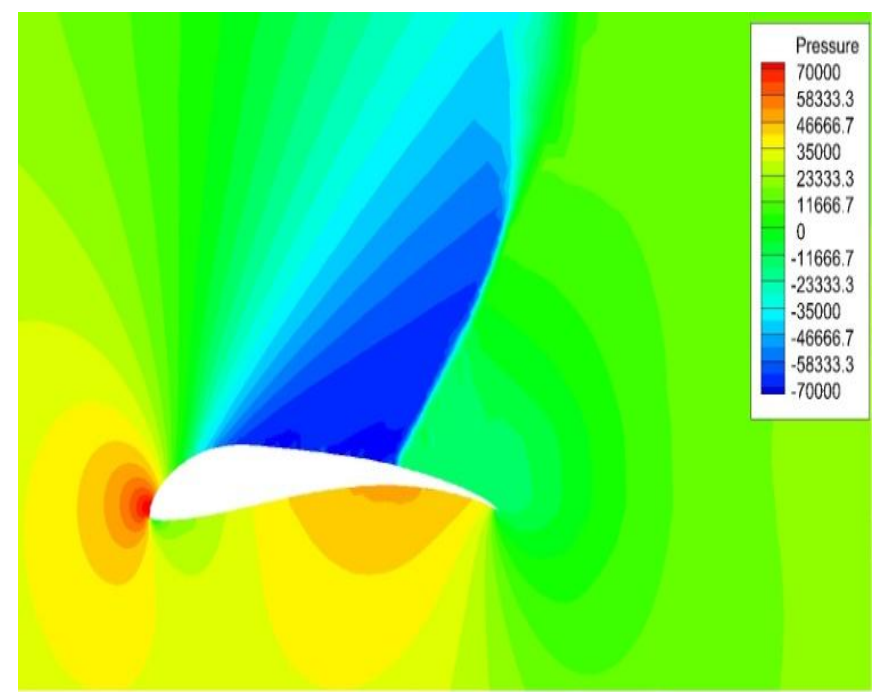

Fig 14: Pressure variation in S1223RTL airfoil geometry at $\mathrm{M}=0.8$ and $\alpha=12^{\circ}$

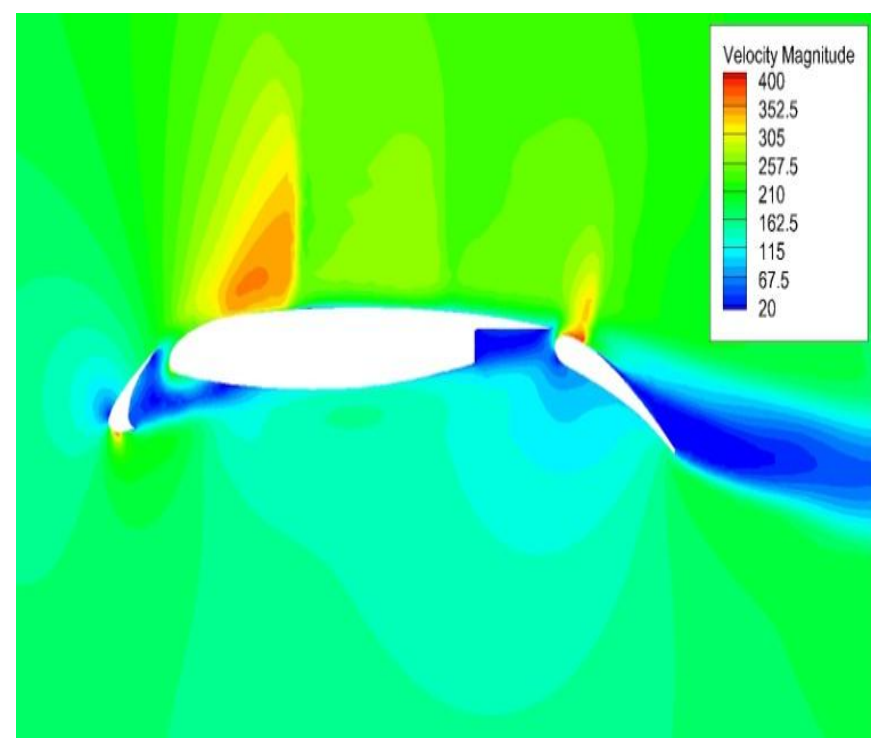

Fig 15: Velocity variation in MDA30P30N airfoil geometry at $\mathrm{M}=0.6$ and $\alpha=0^{\circ}$

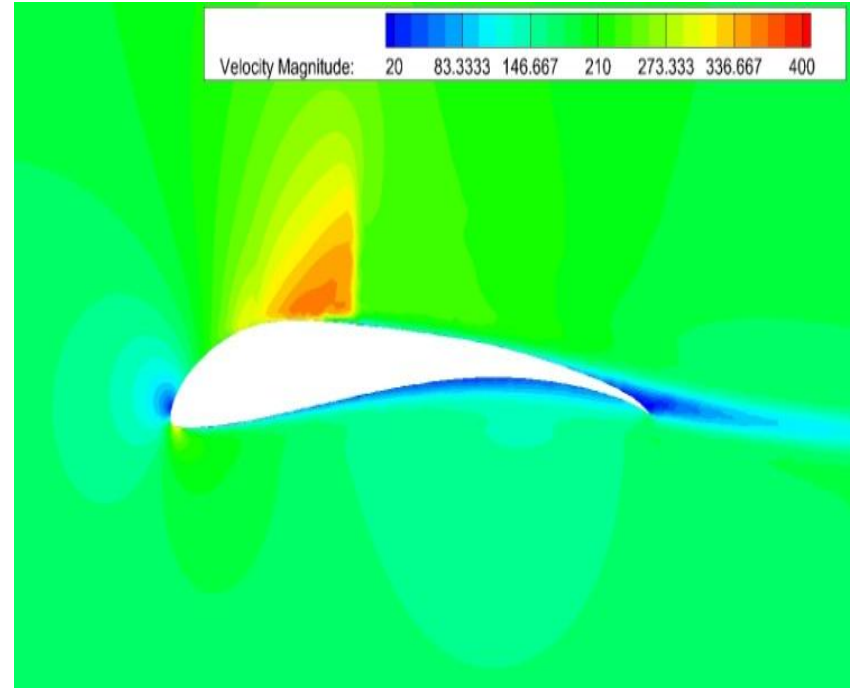

Fig 16: Velocity variation in S1223RTL airfoil geometry at $\mathrm{M}=0.6$ and $\alpha=0^{\circ}$

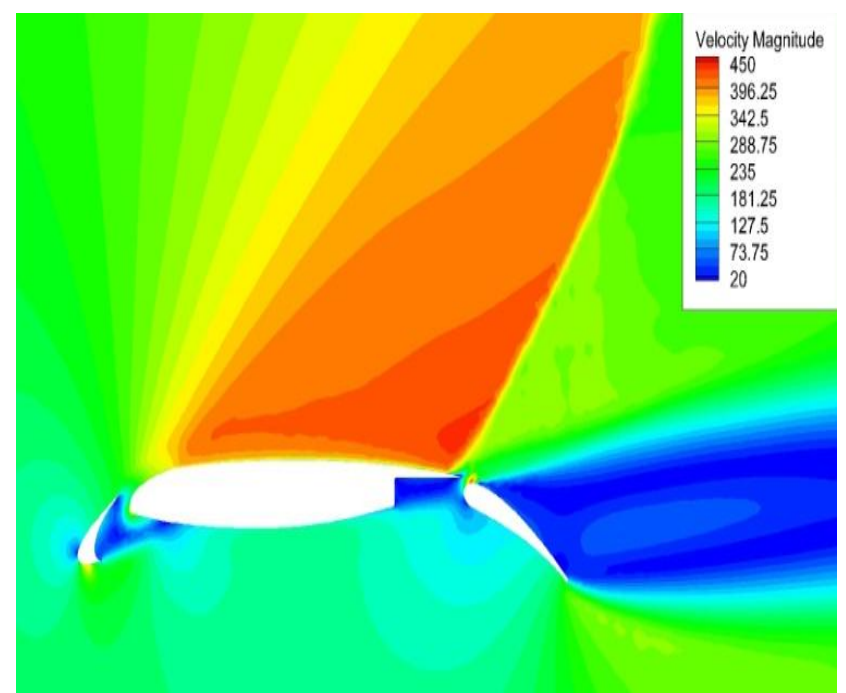

Fig 17: Velocity variation in MDA30P30N airfoil geometry at $\mathrm{M}=0.8$ and $\alpha=8^{\circ}$

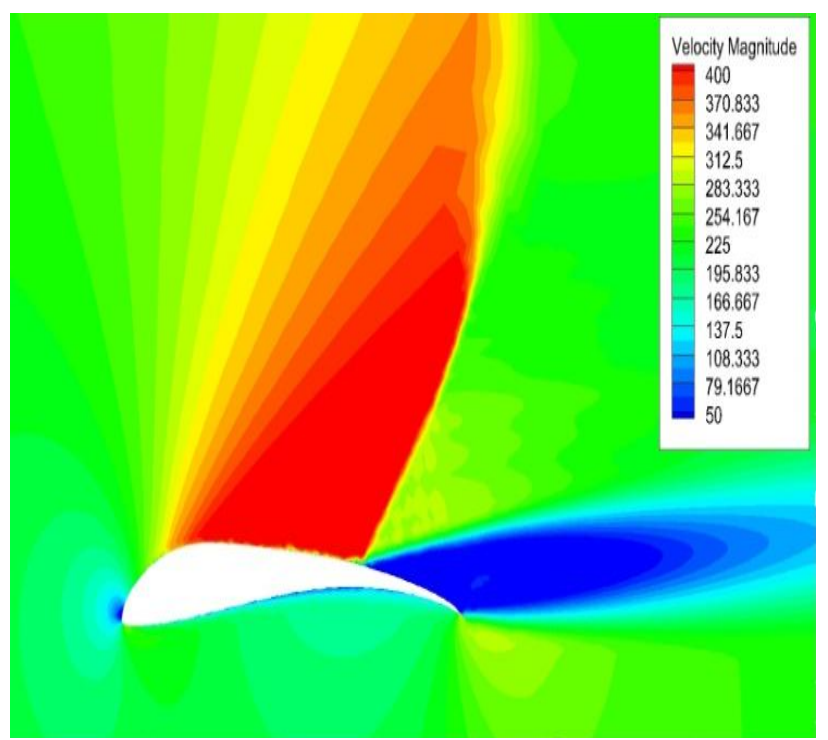

Fig 18: Velocity variation in S1223RTL airfoil geometry at $\mathrm{M}=0.8$ and $\alpha=12^{\circ}$ 


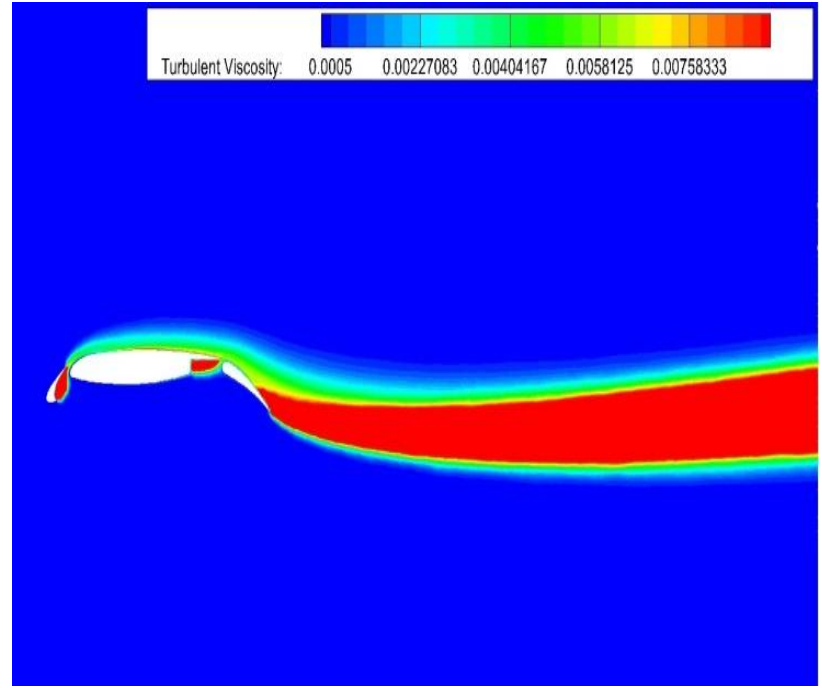

Fig 19: Turbulent viscosity variation in MDA30P30N airfoil geometry at $\mathrm{M}=0.2$ and $\alpha=8^{\circ}$

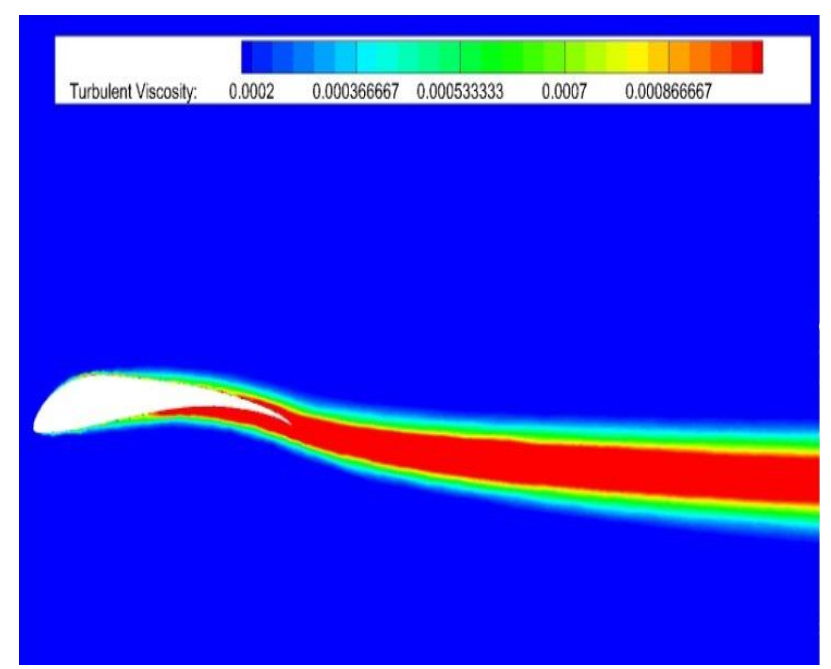

Fig 20: Turbulent viscosity variation in S1223RTL airfoil geometry at $\mathrm{M}=0.2$ and $\alpha=0^{\circ}$

Figure 21,22,23 and 24 shows the streamline formation around both the airfoil geometries. As seen from the figure, in MDA30P30N there is eddy loops formation in the gaps between the slat and main body, the main body and flap, and also after flaps. As the Mach number and Angles of attack increases the eddy loops gets more and denser around the regions which result in the increase in drag. In the case of S1223RTL, the eddy loops formation occurs at the trailing edge of the main body geometry. Similar to MDA30P30N, the intensity of eddy loops increases as the Mach Number and Angles of attack is increased and add on to the increment of drag. Eddy loop formation occurs due to discontinuation in the airfoil geometries, the streamlines around the body is not smooth.

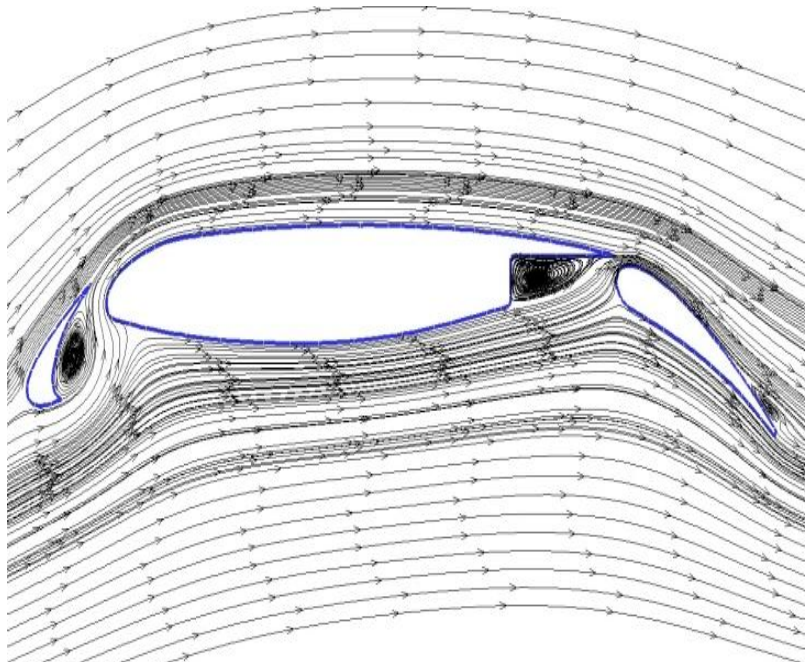

Fig 21: Eddy Loop formation in MDA30P30N airfoil geometry at $\mathrm{M}=0.2$ and $\alpha=4^{\circ}$

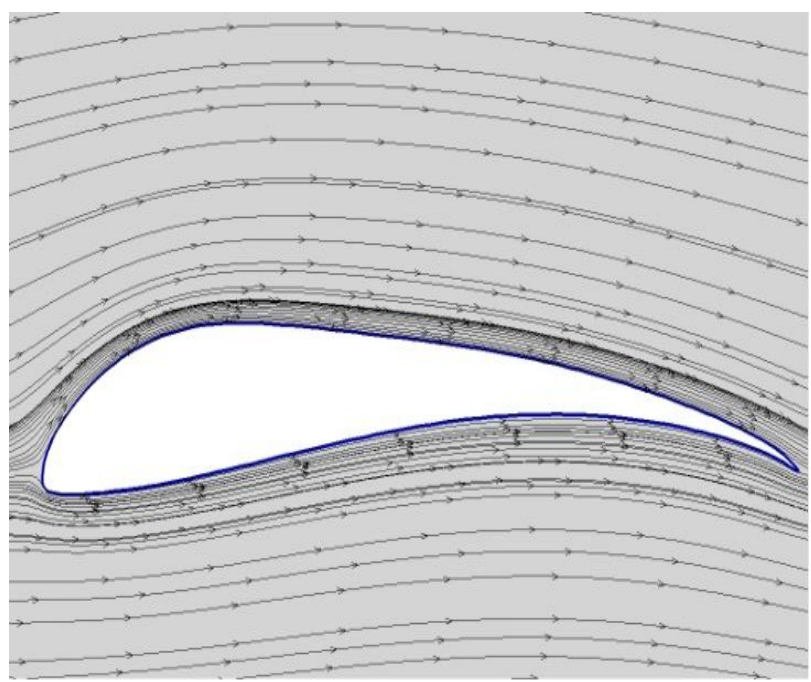

Fig 22: Eddy Loop formation in S1223RTL airfoil geometry at $\mathrm{M}=0.2$ and $\alpha=0^{\circ}$

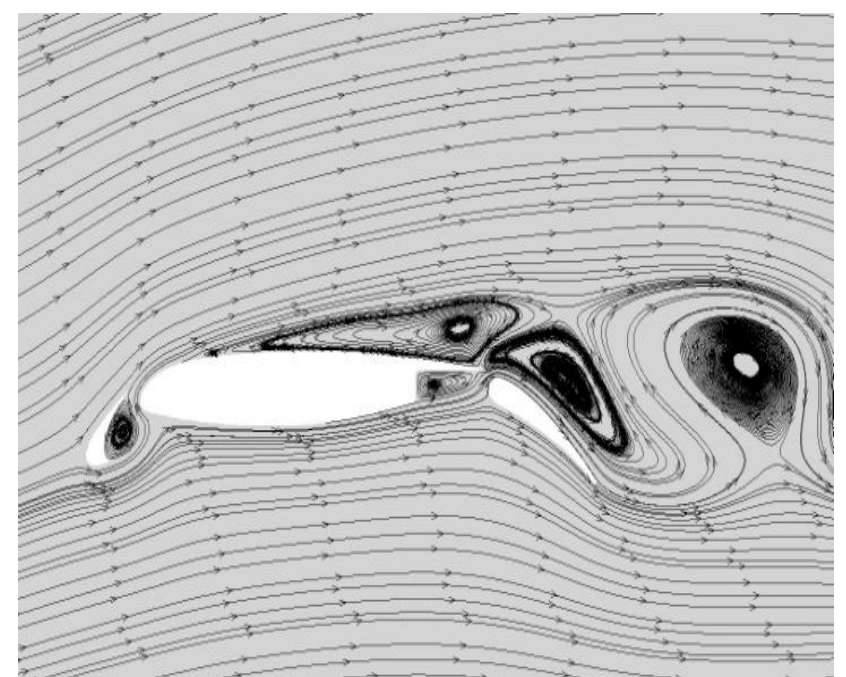

Fig 23: Eddy Loop formation in MDA30P30N airfoil geometry at $\mathrm{M}=0.6$ and $\alpha=8^{\circ}$ 


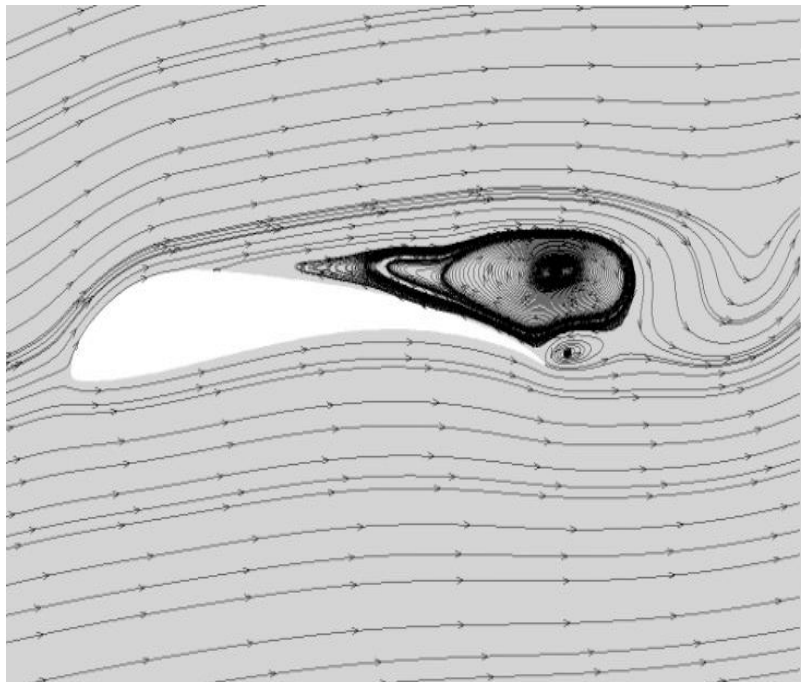

Fig 24: Eddy Loop formation in S1223RTL airfoil geometry at $\mathrm{M}=0.6$ and $\alpha=8^{\circ}$

Figure 25 and 26 show the $\mathrm{C}_{\mathrm{L}}$ vs. $\alpha$ plot of MDA30P30N and S1223RTL. It can be seen that the $\mathrm{C}_{\mathrm{L}}$ of MDA30P30N increases till $\alpha=20^{\circ}$ and then starts decreasing in all the 3 cases of Mach numbers. Therefore, it can be said that the stalling angle or lift break for MDA30P30N lies between $\alpha=20^{\circ}$ and $\alpha=24^{\circ}$, but as the Mach number increases the set of values of $\mathrm{C}_{\mathrm{L}}$ decreases. In the case of S1223RTL, $\mathrm{C}_{\mathrm{L}}$ value increases till $\alpha=12^{\circ}$ then decreases. Therefore, it can be inferred that the stalling angle of S1223RTL lies between $\alpha=12^{\circ}$ and $\alpha=16^{\circ}$, it can also be seen that for $M=0.6$ and $\mathrm{M}=0.8$ the set of values of $\mathrm{C}_{\mathrm{L}}$ is less than that of a set of $\mathrm{C}_{\mathrm{L}}$ values for $\mathrm{M}=0.2$.

Figure 27 and 28 depicts the $\mathrm{C}_{\mathrm{D}}$ vs. $\alpha$ plot of MDA30P30N and S1223RTL. As can be seen, the $C_{D}$ of MDA30P30N shows a small dip at first and then increases as the Mach number is increased with increasing angles of attack. Similar is the case with S1223RTL, but a sudden rise in $C_{D}$ can be noticed at $\alpha=16^{\circ}$ for $M=0.2$, which is more than the $C_{D}$ given by the same airfoil for $\mathrm{M}=0.6$ and $\mathrm{M}=0.8$.

Figure 29,30 and 31 shows the comparison of $\mathrm{C}_{\mathrm{L}}$ vs. $\alpha$ of both MDA30P30N and S1223RTL, as can be seen from the figures at $M=0.2, M=0.6$ and $M=0.8$ respectively, the $C_{L}$ for both the airfoil section increases till $\alpha=12^{\circ}$ after which the $\mathrm{C}_{\mathrm{L}}$ of MDA30P30N keeps on increasing and the $\mathrm{C}_{\mathrm{L}}$ of S1223RTL drops by the time it reaches $\alpha=16^{\circ}$. Comparing both the cases it is evident that MDA30P30N generates more lift in all 3 cases of Mach Number. Table 3 and Table 4 shows tabulated values of $\mathrm{C}_{\mathrm{L}}$ and $\mathrm{C}_{\mathrm{D}}$ for MDA30P30N and S1223RTL at different Mach Numbers and Angles of Attack respectively. Each value of $\mathrm{C}_{\mathrm{L}}$ and $\mathrm{C}_{\mathrm{D}}$ in the Table 3 and Table 4 was obtained when each simulation had reached its convergence point.

Similarly, Figure 32,33 and 34 shows the comparison of $\mathrm{C}_{\mathrm{D}}$ vs. $\alpha$ of both MDA30P30N and S1223RTL, as seen from the figures at $\mathrm{M}=0.2, \mathrm{M}=0.6$, and $\mathrm{M}=0.8$ respectively. At $\mathrm{M}=0.2$, as seen from Figure 32 the $\mathrm{C}_{\mathrm{D}}$ of MDA30P30N is more at the beginning angles of attack, but as it is increased it can be seen that the $C_{D}$ of S1223RTL increases rapidly than compared to MDA30P30N. At $\mathrm{M}=0.6$ and $\mathrm{M}=0.8$, as seen from Figure 33 and 34 the $\mathrm{C}_{\mathrm{D}}$ value of S1223RTL is more than MDA30P30N in the beginning but as the angle of attack is increased the $C_{D}$ of S1223RTL drops till a certain point and then again starts increasing and the $C_{D}$ value of MDA30P30N shows an increase consistently throughout the increase of angles of attack.

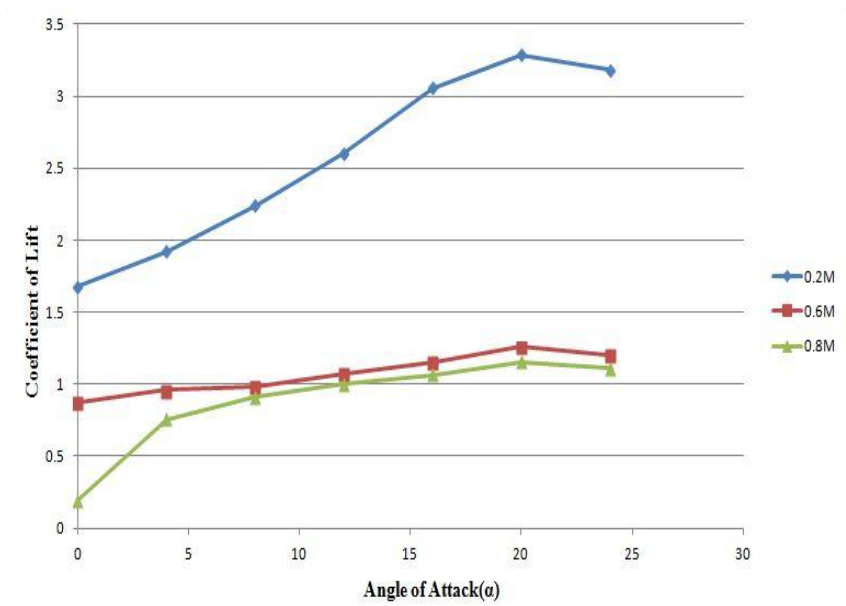

Fig 25: MDA30P30N Lift Coefficient $\left(\mathrm{C}_{\mathrm{L}}\right)$ vs. Angle of $\operatorname{attack}(\alpha)$ for $M=0.2, M=0.6$ and $M=0.8$

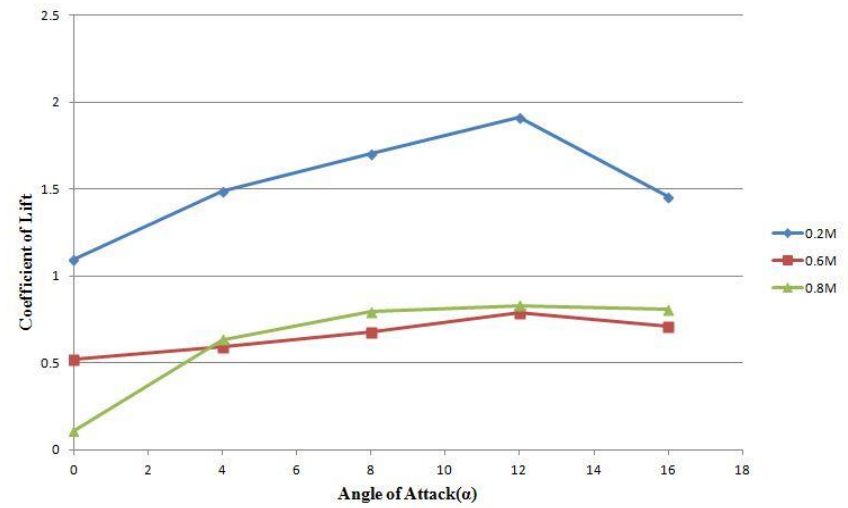

Fig 26: S1223RTL Lift Coefficient $\left(C_{L}\right)$ vs. Angle of $\operatorname{attack}(\alpha)$ for $M=0.2, M=0.6$ and $M=0.8$

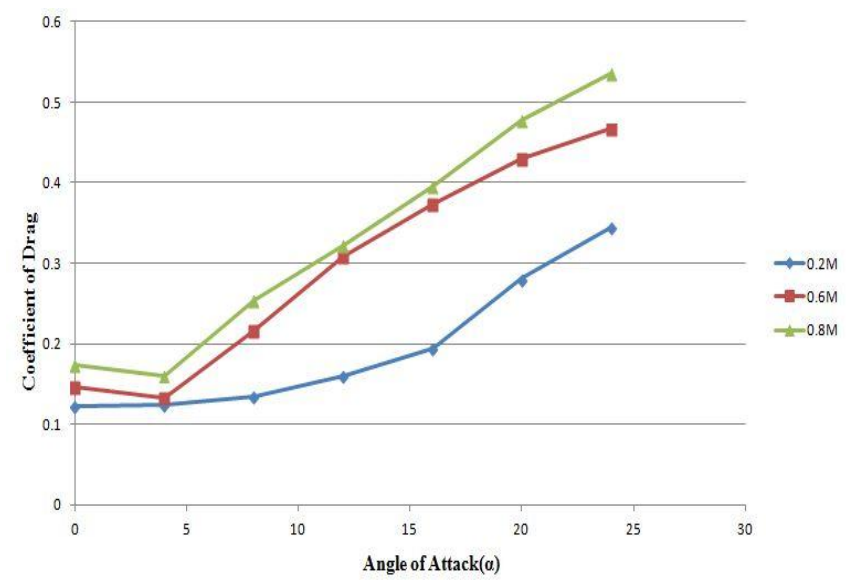

Fig 27: MDA30P30N Drag Coefficient $\left(\mathrm{C}_{\mathrm{D}}\right)$ vs. Angle of $\operatorname{attack}(\alpha)$ for $M=0.2, M=0.6$ and $M=0.8$ 


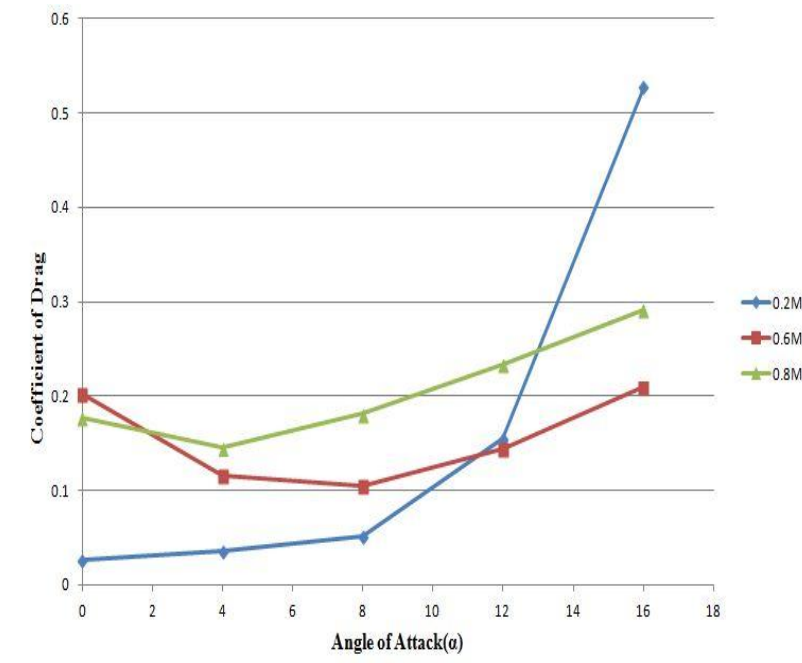

Fig 28: S1223RTL Drag Coefficient $\left(C_{D}\right)$ vs. Angle of $\operatorname{attack}(\alpha)$ for $M=0.2, M=0.6$ and $M=0.8$

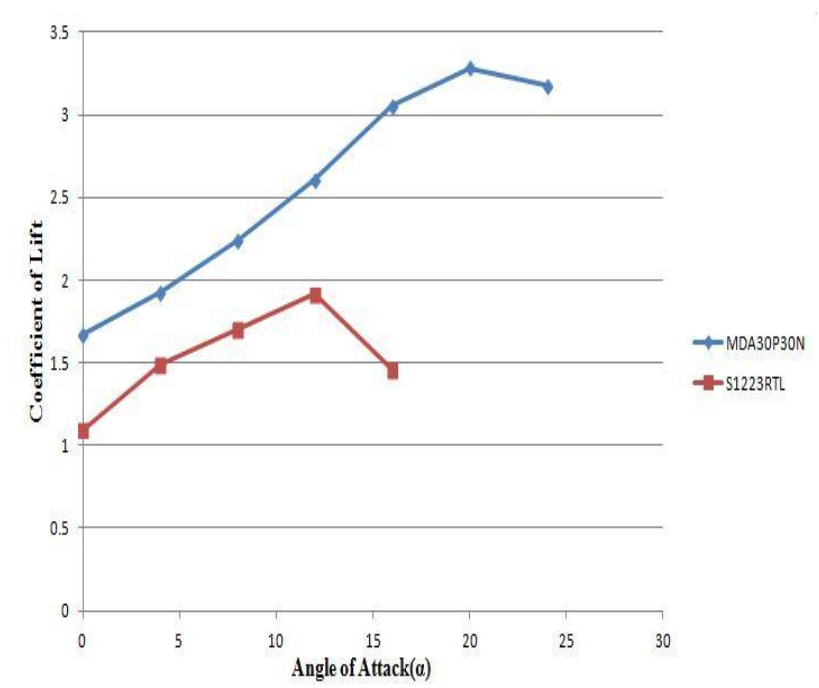

Fig 29: Comparison of Lift Coefficient $\left(C_{L}\right)$ vs. Angle of $\operatorname{attack}(\alpha)$ at $\mathrm{M}=0.2$

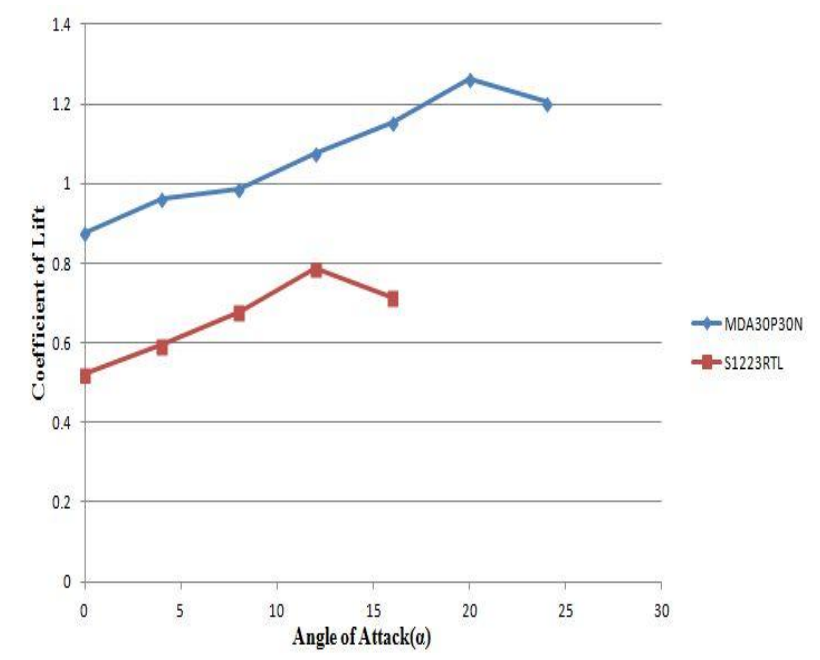

Fig 30: Comparison of Lift Coefficient $\left(C_{L}\right)$ vs. Angle of $\operatorname{attack}(\alpha)$ at $M=0.6$

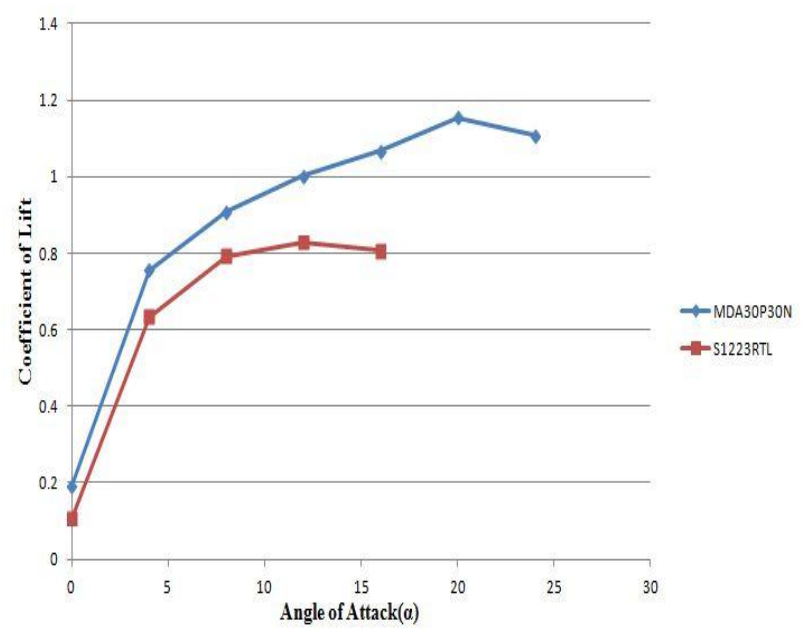

Fig 31: Comparison of Lift Coefficient $\left(C_{L}\right)$ vs. Angle of $\operatorname{attack}(\alpha)$ at $\mathrm{M}=0.8$

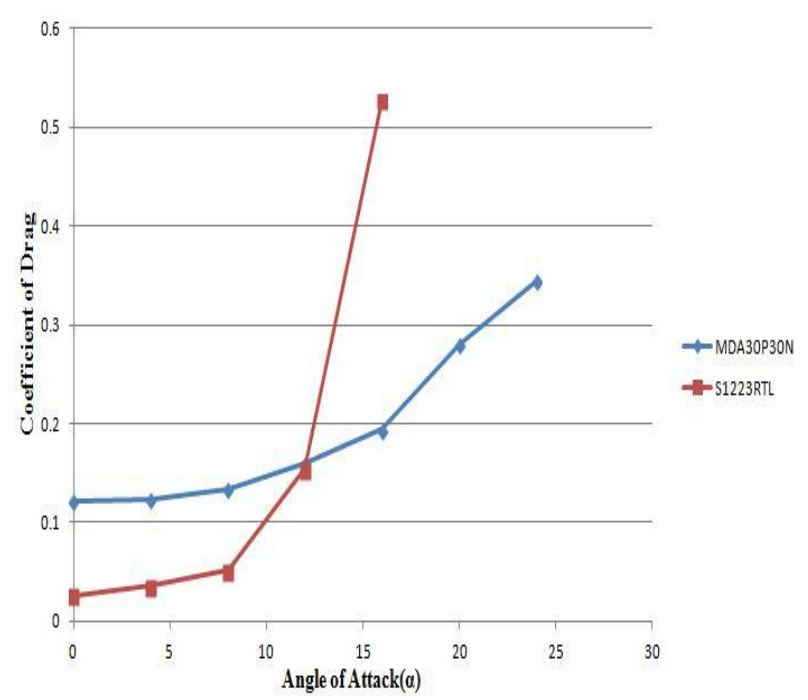

Fig 32: Comparison of Drag Coefficient $\left(C_{D}\right)$ vs. Angle of $\operatorname{attack}(\alpha)$ at $\mathrm{M}=0.2$

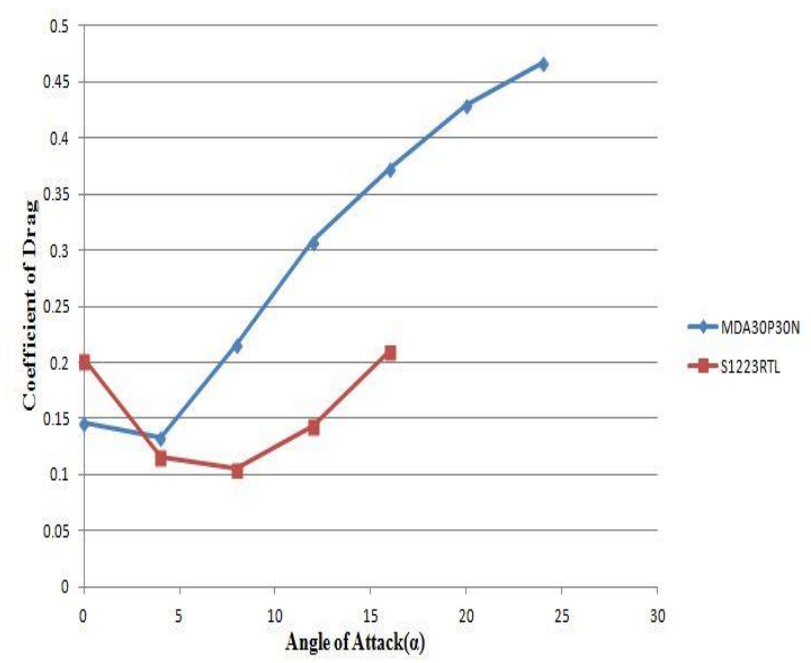

Fig 33: Comparison of Drag Coefficient $\left(C_{D}\right)$ vs. Angle of $\operatorname{attack}(\alpha)$ at $\mathrm{M}=0.6$ 


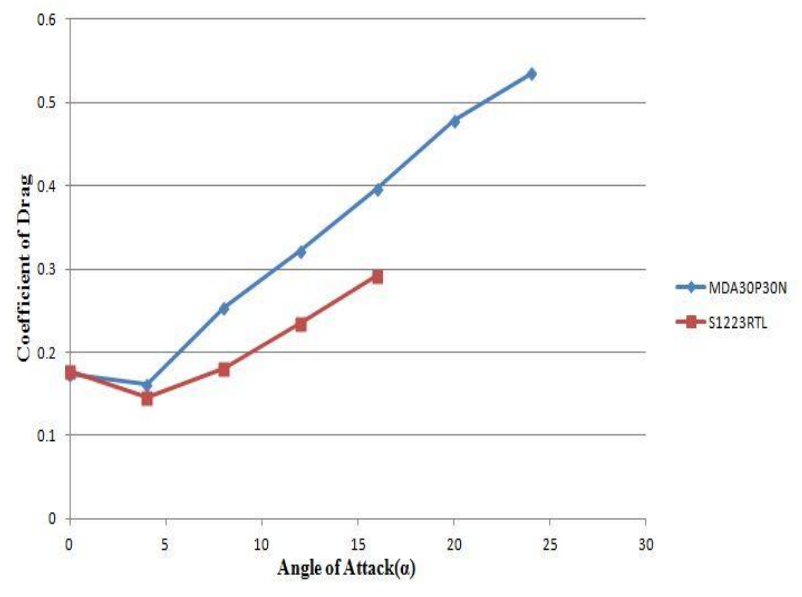

Fig 34: Comparison of Drag Coefficient $\left(C_{D}\right)$ vs. Angle of $\operatorname{attack}(\alpha)$ at $\mathrm{M}=0.8$

Table 3: MDA30P30N Airfoil $C_{L} \& C_{D}$ Values

\begin{tabular}{|c|c|c|c|}
\hline \multicolumn{4}{|c|}{ MDA30P30N } \\
\hline $\begin{array}{l}\text { Mach } \\
\text { Number(M) }\end{array}$ & $\begin{array}{l}\text { Angle of } \\
\operatorname{Attack}(\alpha)\end{array}$ & $\mathbf{C}_{\mathrm{L}}$ & $\mathbf{C}_{\mathrm{D}}$ \\
\hline \multirow{7}{*}{0.2} & $0^{\circ}$ & 1.676 & 0.12202 \\
\hline & $4^{\circ}$ & 1.9229 & 0.1236 \\
\hline & $8^{\circ}$ & 2.2403 & 0.13432 \\
\hline & $12^{\circ}$ & 2.6044 & 0.15988 \\
\hline & $16^{\circ}$ & 3.0552 & 0.19374 \\
\hline & $20^{\circ}$ & 3.2841 & 0.28058 \\
\hline & $24^{\circ}$ & 3.1808 & 0.3438 \\
\hline \multirow{7}{*}{0.6} & $0^{\circ}$ & 0.87671 & 0.14668 \\
\hline & $4^{\circ}$ & 0.96108 & 0.13312 \\
\hline & $8^{\circ}$ & 0.98508 & 0.21658 \\
\hline & $12^{\circ}$ & 1.0751 & 0.30822 \\
\hline & $16^{\circ}$ & 1.153 & 0.37298 \\
\hline & $20^{\circ}$ & 1.2615 & 0.42965 \\
\hline & $24^{\circ}$ & 1.2042 & 0.46667 \\
\hline \multirow{7}{*}{0.8} & $0^{\circ}$ & 0.19223 & 0.174256 \\
\hline & $4^{\circ}$ & 0.7565 & 0.1608 \\
\hline & $8^{\circ}$ & 0.9093 & 0.25363 \\
\hline & $12^{\circ}$ & 1.0009 & 0.32192 \\
\hline & $16^{\circ}$ & 1.0661 & 0.3959 \\
\hline & $20^{\circ}$ & 1.1546 & 0.47775 \\
\hline & $24^{\circ}$ & 1.1094 & 0.5350 \\
\hline
\end{tabular}

Table 4: MDA30P30N Airfoil $C_{L} \& C_{D}$ Values S1223RTL

\begin{tabular}{|l|l|l|l|}
\hline $\begin{array}{l}\text { Mach } \\
\text { Number(M) }\end{array}$ & $\begin{array}{l}\text { Angle of } \\
\text { Attack(a) }\end{array}$ & $\mathbf{C}_{\mathbf{L}}$ & $\mathbf{C}_{\mathbf{D}}$ \\
\hline \multirow{5}{*}{0.2} & $0^{\mathrm{o}}$ & 1.0974 & 0.026128 \\
\cline { 2 - 4 } & $4^{\mathrm{o}}$ & 1.4889 & 0.035899 \\
\cline { 2 - 4 } & $8^{\mathrm{o}}$ & 1.7038 & 0.051677 \\
\cline { 2 - 4 } & $12^{\mathrm{o}}$ & 1.913 & 0.15441 \\
\hline
\end{tabular}

\begin{tabular}{|l|l|l|l|}
\hline & $16^{\mathrm{o}}$ & 1.4587 & 0.5273 \\
\hline \multirow{4}{*}{0.6} & $0^{\mathrm{o}}$ & 0.52143 & 0.20219 \\
\cline { 2 - 4 } & $4^{\mathrm{o}}$ & 0.59443 & 0.11624 \\
\cline { 2 - 4 } & $8^{\mathrm{o}}$ & 0.67726 & 0.10494 \\
\cline { 2 - 4 } & $12^{\mathrm{o}}$ & 0.78666 & 0.14386 \\
\cline { 2 - 4 } & $16^{\mathrm{o}}$ & 0.7135 & 0.209585 \\
\hline \multirow{5}{*}{0.8} & $0^{\mathrm{o}}$ & 0.10769 & 0.177373 \\
\cline { 2 - 4 } & $4^{\mathrm{o}}$ & 0.63403 & 0.14497 \\
\cline { 2 - 4 } & $8^{\mathrm{o}}$ & 0.79318 & 0.18147 \\
\cline { 2 - 4 } & $12^{\mathrm{o}}$ & 0.82899 & 0.23394 \\
\cline { 2 - 4 } & $16^{\mathrm{o}}$ & 0.80669 & 0.29131 \\
\hline
\end{tabular}

\section{CONCLUSION}

In this paper, comparative analysis of two high lift airfoil geometries viz. MDA30P30N and S1223RTL has been carried out at conditions similar to the altitude at $40,000 \mathrm{ft}$, with 3 different Mach Numbers and different Angles of Attack. From the analysis and comparing both the airfoils, it is evident that MDA30P30N generates more lift in all 3 cases of Mach Numbers. Thus, it can be concluded that MDA30P30N, which a multi element airfoil is more aerodynamically stable and efficient in generating more lift than high lift generating single element airfoil S1223RTL and for real life application, the usage of multi-element airfoils will result in better wing formation in the general aviation airplanes.

\section{REFERENCES}

[1]. Zhenhui Zhang, Dong Li. "Numerical investigation of flow over multi-element airfoils with lift-enhancing tabs", 28th International Congress of the Aeronautical Sciences(2012), ICAS 2012-2.3.2.

[2]. Udaya Kumar D, Kannan S, Vimal Chand D, Sriram R and Ganapathi C. "Aerodynamic analysis of multi element airfoil", Journal of Aeronautics \& Aerospace Engineering(2016), Volume 5 , Issue 2, ISSN: 2168-9792.

[3]. Christopher L. Rumsey, Elizabeth M. Lee-Rausch, and Ralph D. Watson. "Three-dimensional effects on multielement high lift computations", $40^{\text {th }}$ American Institute of Aeronautics and Astronautics Aerospace Sciences Meeting \& Exhibit (2002), AIAA paper 2002-0845.

[4]. Sumeet Sharma "An aerodynamic comparative analysis of airfoils for low-speed aircrafts", International Journal of Engineering Research \& Technology(2016), ISSN: 22780181, Vol. 5, Issue 11.

[5]. W. K. Anderson, Daryl L. Bonhaus, Robert J. McGhee, and Betty S. Walker. "Navier-Stokes computations and experimental comparisons for multielement airfoil configurations", Journal of Aircraft, Vol. 32, No. 6 (1995), pp. 1246-1253.

[6]. Prashant J Ambhore, Sawpnil Mali. "Multi Element Wing Analysis", IOSR Journal of Mechanical and Civil Engineering (IOSR-JMCE), Volume 13, Issue 2 Ver. I (Mar. - Apr. 2016), PP 95-100.

[7]. Sangho Kim, Juan J. Alonso, and Antony Jameson. "Design optimization of high-lift configurations using a viscous continuous adjoint method", $40^{\text {th }}$ American Institute of Aeronautics and Astronautics Aerospace Sciences Meeting \& Exhibit (2002), AIAA paper 2002-0844 
[8]. Mohammad Hazrin bin Ismail and Shamsul Anuar bin Shamsudin. "Design and analysis of shape-changing slat of 30P30N airfoil", Malaysian Technical Universities Conference on Engineering \& Technology $\left(8^{\text {th }}\right.$ MUCET 2014), Volume 1, e-ISBN: 978-967-0257-53-2

[9]. João Alves de Oliveira Neto, Darci Cavali, Carlos Breviglieri Júnior, João Luiz F. Azevedo and Ana Lúcia Fernandes de Lima e Silva. "Computational simulations of high-lift configurations using unstructured grids", $11^{\text {th }}$ Brazilian Congress of Thermal Sciences and Engineering ENCIT 2006, Paper CIT06-0269

[10]. UIUC Applied Aerodynamics Group Webpage [Online].. Available: http://mselig.ae.illinois.edu/ads_history.html

[11].Aifoil Tools Webpage [Online]. Available: http://airfoiltools.com/airfoil/details?airfoil=s1223rtl-il

[12]. The Engineering Toolbox Webpage [Online]. Available:

http://www.engineeringtoolbox.com/international-standardatmosphere-d_985.html (ISA Calculator)

\section{BIOGRAPHIES}

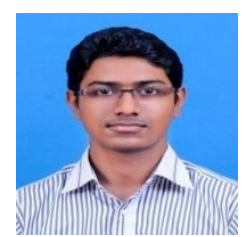

ARAVIND SATHEESH KUMAR, a third year student of B.Tech Aerospace Engineering at the SRM University, Kanttankulathur, Tamil Nadu, is pursuing an Undergraduate degree in Aerospace engineering. Former engineering apprentice at Hindustan Aeronautics Limited (HAL), Nasik division.

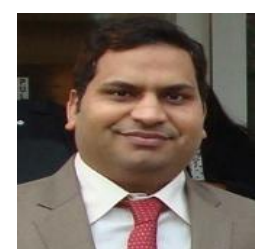

TARUN YADAV, Senior Manager at Design Armament Department, Aircraft Upgrade Research and Design Centre (AURDC), Hindustan Aeronautics Limited (HAL), Nasik Division. Degree holder of Master of Science (M.Sc) in Computational Fluid Dynamics from Cranfield University, United Kingdom.

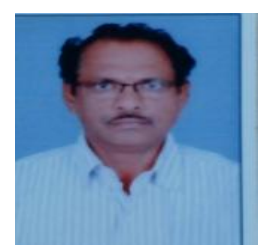

BHARAT SINGH MANDLOI, working as Scientist-F at RCMA, Nasik. He is having experience of about 25 years in Airworthiness certification of Russian origin military aircraft. Degree holder of Master of Technology (M.Tech) from Indian Institute of Technology, Kharagpur (WB), India. Presently pursuing PhD from IIT, Kharagpur (WB), India.

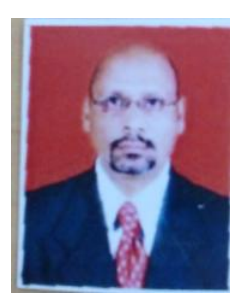

R.P KHAPLI, working as AGM, Aircraft Upgrade Research and Design Centre (AURDC), Hindustan Aeronautics Limited (HAL), Nasik Division. Degree holder of Bachelor in Engineering (BE) from Govt. college of Engineering, Amravati, Nagpur University, India. 